Published in final edited form as:

Soc Sci Med. 2016 December ; 171: 94-102. doi:10.1016/j.socscimed.2016.11.006.

\title{
Increased drug use and the timing of social assistance receipt among people who use illicit drugs
}

\author{
Emanuel Krebs ${ }^{a}$, Linwei Wang ${ }^{a}$, Michelle Olding ${ }^{a}$, Kora DeBeck ${ }^{a, b}$, Kanna Hayashia,c, M-J \\ Milloy $^{\mathrm{a}, \mathrm{c}}$, Evan Wood ${ }^{\mathrm{a}, \mathrm{c}}$, Bohdan Nosyk ${ }^{\mathrm{a}, \mathrm{d}}$, and Lindsey Richardson ${ }^{\mathrm{a}, \mathrm{e}}$ \\ aBC Centre for Excellence in HIV/AIDS; St. Paul's Hospital, 608-1081 Burrard Street, Vancouver, \\ BC, V6Z 1Y6, Canada \\ bSchool of Public Policy, Simon Fraser University; Suite 3271-515 West Hastings Street, \\ Vancouver, BC, V6B 5K3, Canada \\ 'Department of Medicine, Division of AIDS, University of British Columbia; St. Paul's Hospital, \\ 608-1081 Burrard Street, Vancouver, BC, V6Z 1Y6, Canada \\ dFaculty of Health Sciences, Simon Fraser University; 8888 University Drive, Burnaby, BC, V5A \\ 1S6, Canada \\ eDepartment of Sociology, University of British Columbia; 6303 NW Marine Drive, Vancouver, BC, \\ V6T 1Z1, Canada
}

\section{Abstract}

Background-The monthly disbursement of social assistance (SA) payments to people who use illicit drugs (PWUD) has been temporally associated with increases in drug-related harm. Yet, whether SA receipt changes drug use intensity compared to levels of use at other times in the month has not been established. We therefore examined this relationship among PWUD in Vancouver, Canada (2005-2013).

Methods-Data were derived from prospective cohorts of HIV-positive and HIV-negative PWUD. Every six months, participants were asked about their illicit drug use during the last 180 days and the past week. We determined whether SA receipt occurred within the assessment's oneweek recall period. We employed generalized estimating equations controlling for confounders to examine the relationship between SA receipt and the change in drug use intensity, defined as a $100 \%$ increase in the average times per day a given drug was used in the last week compared to the previous 6 months. We tested the robustness of this relationship by stratifying analyses by whether individuals primarily used stimulants, illicit opioids or engaged in polydrug use and examining the timing of SA receipt relative to date of assessment.

Corresponding Author: Bohdan Nosyk, PhD, BC Centre for Excellence in HIV/AIDS, St. Paul's Hospital 613-1081 Burrard St. Vancouver, BC, Canada V6Z 1Y6, bnosyk@ cfenet.ubc.ca, T: 604-806-8649.

Publisher's Disclaimer: This is a PDF file of an unedited manuscript that has been accepted for publication. As a service to our customers we are providing this early version of the manuscript. The manuscript will undergo copyediting, typesetting, and review of the resulting proof before it is published in its final citable form. Please note that during the production process errors may be discovered which could affect the content, and all legal disclaimers that apply to the journal pertain. 
Results-Our study included 2,661 individuals (median age 36, 32\% female) with 1,415 (53.2\%) reporting SA receipt occurring within the one-week recall period of the assessment at least once. SA receipt was independently associated with intensified drug use (Adjusted Odds Ratio [AOR]: 1.79; $95 \%$ Confidence Interval [CI]: 1.53, 2.09), and remained significant when stratified by primary use of stimulants (AOR: 1.87; 95\% CI: 1.54, 2.26), opioids (AOR: 1.96; 95\% CI: 1.23 , 3.13 ) and polydrug use (AOR: 1.53; 95\% CI: 1.11, 2.10).

Conclusion-We found a temporal association between SA receipt and drug use intensification. While the health and social benefits of SA are significant, these findings suggest that alternative disbursement strategies, such as staggered or smaller and more frequent SA payments may be able to mitigate drug-related harm. Alternatives should be tested rigorously.

\section{Keywords}

Canada; social assistance; government transfers; drug use intensity; stimulants; opioids; polydrug use; Vancouver

\section{Introduction}

Many people who use illicit drugs (PWUD) are vulnerable to socio-economic insecurity and face various individual and structural barriers to formal employment, including chronic homelessness, limited formal education or employment skills, workplace drug-testing, criminal record checks, and employer discrimination. (Cebulla, Heaver, Smith, \& Sutton, 2004; Richardson, Wood, \& Kerr, 2013) Social assistance (SA) provides a critical source of income for many PWUD to meet basic needs and alleviate the adverse health effects of poverty. (Immervoll, 2009; Nelson, 2004; Walker, 2004)

Higher income may improve individual health outcomes through its direct influence on material conditions (ability to work, housing, health care access and nutrition) and indirectly by enabling control over life situations. (Deaton, 2002; Marmot, 2004) However, observational studies have found that higher income among PWUD is also associated with high-intensity drug use (Bretteville-Jensen \& Sutton, 1996; DeBeck et al., 2007; Deschenes \& Anglin, 1991; Grapendaal, Lewu, \& Nelen, 1995; Sherman \& Latkin, 2002), suggesting a more complex relationship between income and drug use. While this association may be explained in part by the need for individuals with higher intensity drug addiction to generate more income in order to meet their drug use needs (Bourgois, 1998; Deering et al., 2013; Maher, 1997), observational studies also suggest that some income generation strategies can contribute to higher intensity drug use or create additional barriers to decreasing drug use. Specifically, research from Vancouver, Canada (DeBeck et al., 2011; Kerr T et al., 2008; Long et al., 2014) and other settings (Bretteville-Jensen \& Sutton, 1996; Fischer B, 1999; Grapendaal et al., 1995; Sherman \& Latkin, 2002) suggest that people who self-report high intensity drug use are more likely to report income from street-based activities such as sex work and drug-dealing. Engagement in street-based activities may impede decreasing drug use (Ti L, 2014), directly when individuals are paid in drugs rather than money (BrettevilleJensen \& Sutton, 1996; Shannon K et al., 2008; Small et al., 2013) and indirectly as individuals may increase drug use in response to work stresses (Draus PJ, 2010; Erikson P, 2002). Taken together, this body of research suggests the potential for reverse causality in 
the income and drug intensity relationship: higher intensity drug use may lead individuals to generate income, but income generation strategies (particularly from sex work and drug dealing) may in turn contribute to higher intensity drug use. The hypothesized reversecausality, or endogeneity of income in the demand for illicit drugs, challenges efforts to isolate the competing directional effects of the drug use-income relationship empirically, which are necessarily conflated in observational studies not explicitly addressing income endogeneity. Monthly SA disbursements provide a valuable opportunity to analyze the effect of income on illicit drug use. This source of income is made available at a predictable, exogenously-determined time, not motivated by prior drug use, thus precluding the endogeneity likely implicated in other income generating activities. Here, we use the fact that the Government of British Columbia issues SA to nearly all eligible recipients once a month on the same day, similar to many other North American jurisdictions (Li, Sun, Marsh D. C., \& Anis, 2007). In British Columbia, SA is distributed by the BC Ministry of Social Development and Social Innovation, generally on the last Wednesday of each month (Province of British Columbia, 2016b), and rates are contingent on recipient age, family size, and disability status (Province of British Columbia, 2016a). The SA program is structured as a program of last resort for persons who have exhausted other means of legal financial support, and applicants must have expended nearly all assets to become eligible (Tweddle, Battle, \& Torjman, 2015). Frozen since the last rate increase in 2007 (Tweddle et al., 2015), three general levels of assistance are disbursed: single "employable" individuals receive $\$ 610.00 \mathrm{CAD}$ per month, those classified as persons facing persistent multiple barriers receive $\$ 657.92$ CAD per month and Persons with Disability receive $\$ 906.42$ per month (Province of British Columbia, 2016a). Rates are inclusive of a shelter allowance of $\$ 375$ CAD per month, with the remainder provided as a support allowance (Province of British Columbia, 2016a). Even after considering income from additional provincial tax credits, rates fall between 28-60\% of Canadian thresholds for after-tax low income cut off (Tweddle et al., 2015). Further, individuals in Vancouver face some of the highest costs of living in Canada (The Economist Data Team, 2016), including some of the highest housing costs and lowest vacancy rates in the world (Canada Mortgage and Housing Corporation, 2015).

Consistent with the evidence identifying a complex drug use-income relationship, and given the difficulty of observing drug use, a number of studies have linked monthly SA disbursement to cyclical and substantial increases in the risk of experiencing drug-related harms, including accidental overdose (Otterstatter, Amlani, Guan, Richardson, \& Buxton, 2016; Riddell \& Riddell, 2006; Verheul, Singer, \& Christenson, 1997; Zlotorzynska et al., 2014), hospitalizations (Dobkin \& Puller, 2007; Halpern \& Mechem, 2001; Maynard C, 2000), drug-induced psychiatric emergency department visits (Catalano \& McConnell, 1999; Pickett T, 2015), HIV and substance abuse treatment interruption (Anis et al., 2002; Chan et al., 2004; Svikis, Pickens, Schweitzer, Johnson, \& Haug, 1999), and related burdens on health, social and police services (Brunette, Kominsky, \& Ruiz, 1991; Li et al., 2007; Pickett T, 2015; Riddell \& Riddell, 2006; Shaner et al., 1995; Verheul et al., 1997; Zlotorzynska et al., 2014). While the aforementioned studies used predominantly administrative data, studies examining the drug use-income relationship that directly account for drug use are rare. For example, a study examining the probability of use of cocaine or 
opioids among former recipients of supplemental security income who had received disability benefits for drug addiction and alcoholism in 1996 found a higher probability of a positive urinalysis test in the first 10 days of the month compared to later in the month, with no difference between individuals requalifying for supplemental security income and those losing their benefits (Swartz, Hsieh, \& Baumohl, 2003). However, their outcome examined the association between the timing of SA disbursements and the likelihood of any drug use, as opposed to changes in levels of drug use. Another study among homeless individuals with severe mental illnesses used self-reported measures of illicit drug use drawn from the Addiction Severity Index but examined longitudinal increases in overall drug use associated with SA receipt as opposed to the timing of drug use intensification (Rosen, McMahon, Lin, \& Rosenheck, 2006).

A recent review has pointed out that monthly SA disbursement schedule alters the timing of substance use rather than increase the overall level of use over an extended timeframe (Rosen, 2011). Intensified use immediately following SA receipt may be the cause of much of the drug-related harm identified by observational studies to date. The mechanisms that produce such intensification may be linked to the additional resources available following SA payments for the consumption of drugs, but may also be connected to the broader physical, social, economic, and policy features of the drug use environment (Rhodes, 2009). For example, low levels of income assistance may require individuals to supplement their income from other prohibited and illegal sources such as drug dealing, sex work, or streetbased income generation. The environment in which this activity occurs may increase individual exposures to drug use scenes, which have been associated with economic marginalization and drug-related risk (Richardson et al., 2013). As such, the level of integration in such scenes may amplify individual propensity for increased use, particularly in places where socio-economic marginalization is concentrated and SA receipt is synchronized across the population.

To our knowledge, the proximal relationship between SA receipt and drug use intensity has not been explicitly studied, likely due to the challenge of measuring drug use in the immediate period following SA receipt. If this relationship can be established, it may follow that smaller and more frequent SA disbursements may mitigate the intensification of drug use linked to SA receipt, though this may vary across different drug types (e.g., stimulants, opioids) because of the different patterns of use associated with different substances. Understanding the immediate effect of a monthly SA disbursement on drug use intensity across different types of drug use can thus provide critical insights into how SA policy can be leveraged to reduce drug-related harm among PWUD. Thus, we undertook the current study, which takes advantage of complementary data from three large and long-running prospective cohort studies of PWUD in Vancouver with assessments of both immediate and longer-term drug use intensity, to determine the association between SA receipt and drug use intensity.

\section{Methods}

Data for this analysis were derived from a series of ongoing open prospective cohort studies involving people who use illicit drugs: the At-Risk Youth Study (ARYS); the AIDS Care 
Cohort to evaluate Exposure to Survival Services (ACCESS); and the Vancouver Injection Drug Users Study (VIDUS). HIV-seronegative individuals who inject (VIDUS), HIVseropositive individuals who use (ACCESS) and street-involved youth who use (ARYS) illicit drugs are recruited through word of mouth, street out-reach, and referrals (Strathdee et al., 1997). VIDUS and ACCESS began recruitment in 1996, with ARYS initiating in 2005. The three cohorts, including recruitment and follow-up assessments, have been described in detail previously (Strathdee et al., 1997; Tyndall et al., 2003; Wood, Stoltz, Li, Montaner, \& Kerr, 2006; Wood, Stoltz, Montaner, \& Kerr, 2006). Briefly, individuals are eligible for the study if they live in Greater Vancouver at the time of enrolment, injected (VIDUS) or used (ACCESS and ARYS) illicit drugs other than cannabis in the previous month, are between 14 and 26 (ARYS) or greater than 18 (VIDUS and ACCESS) years of age and provided written informed consent. At baseline and semi-annual follow-up, individuals complete an interviewer-administered questionnaire that elicits information pertaining to sociodemographic characteristics, drug use, treatment utilization, HIV risk behaviors and other exposures and outcomes. Study instruments are coordinated across cohorts to facilitate pooled analyses. Participants also complete a health-specific questionnaire and obtain blood specimens for HIV and Hepatitis C Virus (HCV) serology, and HIV disease monitoring (e.g., CD4 counts, HIV-1 RNA viral load and genotyping) where appropriate. Individuals are offered an honorarium of \$30 CAD for each study visit. All cohort studies have been approved by the University of British Columbia/Providence Health Care Research Ethics Board, and ethical approval for this study was also obtained from the University of British Columbia/Providence Health Care Research Ethics Board and the Simon Fraser University Research Ethics Board.

The study questionnaire collects detailed information about illicit drug use in the previous six months as well as the week prior to the follow-up assessment. Relevant questionnaire items for the current analysis include: "In the last six months, when you were using, which of the following drugs did you use, and how often?"; "In the last six months, on a typical day when you used, how many times did you use?"; "In the last week, how many days did you use this drug?"; "On average - on the days you used - how many times per day did you use during the last week?" Answers for how many times per day a drug was used on average were reported by individuals as integers. We considered data from all observations collected between January 2005 and May 2013. Participants were included if they had a complete baseline assessment but were excluded if they had missing drug use or covariate information at any assessment.

\section{Measures}

Increased illicit drug use-The dependent variable in this analysis was the intensification of drug use in the last week when compared to the previous six months, defined as using at least twice as frequently as usual, measured in terms of the average times per day a drug was used in the last week compared to the average times per day a drug was used in the last six months. Our outcome of interest is constructed as a binary indicator ( $\geq 100 \%$ increase vs $<100 \%$ increase), as our primary concern is with levels of harm which are likely to be greater with larger variations in patterns of use. Given that we do not observe quantity or purity per use, we assume that on average, each time of use is equivalent in terms 
of purity-adjusted quantity. Other thresholds were also considered in sensitivity analyses, as detailed below.

We considered primary drug use, defined as either daily use of a drug or the drug with the highest frequency of use, and classified participants into three categories: Primary use of illicit opioids (heroin, methadone, morphine or other prescription opioids), primary use of stimulants (cocaine, crack cocaine, methamphetamine) and polydrug use. Polydrug use was defined as reporting a combination of more than one primary drug among any of the aforementioned illicit drugs, i.e., daily drug use of more than one substance other than cannabis.

The timing of SA receipt-We first determined whether a monthly SA disbursement was captured within the one-week recall period of the drug use items included in the biannual assessments. We then determined whether SA receipt was reported by participants in the biannual assessment. Therefore, the primary independent variable of interest was a binary indicator of SA receipt occurring within the one-week recall period of the study follow-up assessment compared to either SA receipt occurring outside the one-week recall period or no SA receipt. As such, given SA disbursement occurring on the last Wednesday of every month and biannual assessments occurring only on weekdays excluding the afternoon of SA disbursement days, during which our field office is closed, the binary indicator would capture SA receipt and completion of the biannual assessment on the Thursday following SA disbursement (SA receipt 1 day prior), Friday (SA receipt 2 days prior), Monday (SA receipt 5 days prior), Tuesday (SA receipt 6 days prior) or Wednesday (SA receipt 7 days prior).

Covariates-We considered several additional individual level covariates in our analyses. Self-reported primary source of income at the time of assessment was coded with categories for employment, social assistance, sex work, drug dealing or other acquisitive crime, and street-based income generation (including informal recycling or "binning", car window washing or "squeegeeing", or panhandling). Other potential confounding socio-demographic and risk factors included gender (male vs. female), age (in years), race/ethnicity (white vs. other), history of mental illness (yes vs. no), participation in opioid agonist treatment (i.e., methadone or suboxone) at the time of assessment (yes vs. no), and both HCV and HIV antibody status. Also considered were binary covariates attempting to capture some of the social, structural and environmental elements of the broader risk environment of our study. Included was a binary indicator of a self-report of injecting in a public place such as a street, public lavatory, alley, park, parking lot, or other public setting, which has been associated with physical, social and increased HIV-related risk (Rhodes et al., 2006; Small, Rhodes, Wood, \& Kerr, 2007). Also included was a binary indicator of unstable housing at the time of interview, defined as living in a hotel, hostel, or being homeless; and a binary indicator of residency in the Downtown Eastside (DTES). The DTES has been characterized as an impoverished area with high prevalence of mental illness, illicit drug use, and marginalization. The indicator variable was included due to the large concentration of PWUD, hypothesized to be a cue for intensified drug use in an area with a large proportion of social assistance recipients. 
Statistical Analysis-Our statistical analysis proceeded in four steps. First, we assessed baseline characteristics of participants included in our study and compared the characteristics of those who reported at least once over the study period receiving SA within the one-week recall period of the assessment and those who did not. Second, we compared drug-use patterns and primary source of income from assessments where participants reported SA receipt occurring within the one-week recall period of the assessment with those at which participants did not. In both cases, categorical variables were compared using Pearson's $\chi^{2}$ tests, and continuous variables were compared using Mann-Whitney tests.

Third, we employed generalized estimating equations (GEE) analyses with a logit link and exchangeable covariance matrix to examine the association between reporting SA receipt within the one-week recall period of the assessment and intensified drug use, adjusting for relevant confounders in the multivariable analyses. GEE models were used because of our focus on population average effects at the observation level, and while this approach allowed us to control for individual-level correlation it did not require joint distributional assumptions of the observed data and the individual-level random effects for robust inference (Hubbard et al, 2010). We controlled for primary drug use category in the past 6 months, primary source of income at the time of assessment, gender, age, race/ethnicity, current living conditions (unstable housing, currently residing in the DTES), opioid agonist treatment receipt, injecting in public, and both HCV and HIV antibody status. We also executed stratified analyses according to primary drug use category: illicit opioids, stimulants, or polydrug use.

Lastly, we conducted several sensitivity analyses to determine the robustness of our results. First, we explored the robustness of our results to the temporal association of drug use intensification with SA receipt by examining the timing of SA receipt day-by-day within the one-week recall period of the drug use items. We also considered whether the assessment was completed on the same day as SA receipt or during the two days directly preceding SA receipt, i.e. SA receipt did not occur within the drug use recall window, but followed shortly after assessment, and may therefore also be associated with increases in use leading up to assistance distribution. Second, we used different increase thresholds in drug use frequency compared to the $100 \%$ threshold used in initial analyses. For the lower-bound threshold, we considered previous evidence of health status responsiveness to a $20 \%$ decrease in the Addiction Severity Index (ASI) illicit drug use composite score in establishing our drug use intensification threshold (Nosyk et al., 2010). Given that we were assessing substancespecific change over a shorter time frame than the ASI composite score, we chose a lowerbound threshold of $40 \%$ to account for greater expected variability in short-term intensity of use. For the upper-bound threshold, we chose using three times as much as usual, i.e., a $200 \%$ increase indicator. Third, we estimated our model using a 100\% increase indicator restricted to each individuals' primary drug use, as defined above, to assess if our results were robust to examining only the substance with highest frequency of use. Lastly, to examine the association between the timing of SA receipt and the different ways an individual could increase drug use, we repeated our analyses on an alternative indicator capturing increased frequency of use, defined as a change from less than daily to at least daily use of illicit opioids or stimulants. 
Two-sided p-values were reported and those less than 0.05 were considered statistically significant. All statistical analyses were executed in SAS version 9.4 and figures were produced using $\mathrm{R}$ version 3.2.2.

\section{Results}

A total of 2,919 participants met the study's inclusion criteria. We excluded 258 (8.8\%) due to missing information on drug use history or on covariates of interest in any of their assessments. The 2,661 participants included in the study had 14,961 assessments in the final analytic sample. Among the 2,661 participants included, at baseline the median age was $36,32.4 \%$ were women, $85.8 \%$ had a history of homelessness and $92.7 \%$ reported SA receipt. Participants who were excluded from the study were more likely to be younger, to live outside the DTES, and be part of the ARYS cohort. Excluded participants were less likely to have used injection drugs, experienced non-fatal overdose, and be HIV or HCV seropositive (Supplemental Table A1).

Over a median of 5 follow-up assessments (Inter-Quartile Range [IQR]: 2, 10), 1,415 participants (53.2\%) reported SA receipt within the one-week recall period in 2,859 assessments. Compared to those who never reported SA receipt occurring within the oneweek recall period of the assessment, those who did were more likely to have a history of living in the DTES area and of injecting drugs or overdosing, and being HIV and HCV positive. Table 1 presents detailed baseline characteristics. Figure 1 shows the timing of SA receipt in relation to the one-week drug use recall period and Table 2 presents income and drug use characteristics compared between those who do and do not have a follow up assessment within one week of SA disbursement.

Stimulants were the most commonly-used drugs (65.5\%) and participation in opioid agonist treatment was common $(41.9 \%)$. SA was the most frequently reported primary source of income (63.5\%), followed by street-based income generation, drug dealing or acquisitive crime (15.2\%). Finally, a total of 635 participants (23.9\%) reported at least once over the study period having a $100 \%$ drug use increase in the week prior to interview compared to their assessment of drug use in the previous six months.

In our multivariable analysis, SA receipt within the one-week recall period of assessment was independently associated with drug use intensification (Adjusted Odds Ratio (AOR): 1.79; 95\% Confidence Interval (95\% CI): 1.53, 2.09) (Figure 2). Reporting employment as a primary source of income compared to SA was associated with intensified drug use (AOR: 1.46 ; $95 \%$ CI: 1.11, 1.92), as was reporting injecting in public in the last six months (AOR: $1.49 ; 95 \%$ CI: $1.24,1.78$ ). Table 3 presents detailed results, and factors associated with intensified drug use. When stratified by primary drug use category, SA receipt within the one-week recall period remained independently associated with drug use intensification for all primary use categories, including stimulants (AOR:1.87; 95\% CI: 1.54, 2.26), illicit opioids (AOR: 1.96; 95\% CI: 1.23, 3.13) and polydrug use (AOR: 1.53; 95\% CI: 1.11, 2.10) (Supplemental Table A2). 
Results of the sensitivity analyses conducted day-by-day highlighted a robust temporal relationship between the timing of SA receipt and drug use intensification (Figure 2). SA receipt occurring 1-day as well as 2-, 5-, 6- and 7-days prior to assessment completion (as assessments occurred only on weekdays, there were no observations on the 3- and 4-days prior) were independently associated with drug use intensification (AOR values ranged from 1.54 (95\% CI: 1.16, 2.05) to 2.79 (95\% CI: 1.74, 4.47)) while SA receipt the same day or in the 2 days following assessment completion had a negative association with drug use intensification, although not statistically significant (AOR values ranged from 0.45 (95\% CI: $0.18,1.10)$ to 0.97 (95\% CI: 0.67, 1.14)) (Supplemental Table A3). Results for lower-bound and upper-bound intensification thresholds demonstrated a similar direction of association with a similar magnitude for the $40 \%$ threshold (AOR: $1.81 ; 95 \%$ CI: $1.58,2.07$ ) and a larger magnitude for the $200 \%$ threshold (AOR:2.77; 95\% CI: 2.16, 3.57), suggesting our results were robust to the threshold used. Results were also similar when the $100 \%$ increase indicator was restricted to each individuals' primary drug use (AOR: 1.84; 95 CI: 1.49, 2.26). SA receipt was also independently associated with the alternative indicator capturing increased frequency of use, defined as a change from non-daily to daily use (AOR: 1.32; $85 \%$ CI: 1.04, 1.68). However, when stratified by primary drug category, the association remained significant for stimulant use only (AOR: 1.45; 95\% CI: 1.05, 2.00) (Supplemental Table A4).

\section{Discussion}

Using long-term prospective cohort data from PWUD in Vancouver, Canada, this study has demonstrated a strong temporal association between social assistance receipt and an increase in drug use intensity, compared to levels of use at other times. Additionally, alternate analyses examining day-by-day timing of SA receipt considering potential changes in drug use intensity prior to SA receipt also revealed a consistent temporal pattern characterized by an increased likelihood of immediate drug use intensification following SA receipt and a lower likelihood of increased drug use intensity in the 7-10 days prior to cheque issue. While SA receipt may critically mitigate health harm resulting from extreme poverty, it may also inadvertently contribute to drug-related harm by providing a cue for intensified use. Notably, while results of the current analyses are consistent with previous studies, it is not clear how much of the intensified use is attributable to the individual-level cue of being paid (Epstein et al., 2009) or to the social-level cue of all individuals being paid at the same time (Small et al., 2011; Verheul et al., 1997; Zlotorzynska et al., 2014). In the current study context, previous literature noting the importance of social cues in the overall risk environment for drug-related harm may be of particular relevance in this regard (Rhodes, 2009). While all individuals receive a cue for intensified consumption (Shapiro, 2005; Stephens, 2003), the relative contribution of each of individual and social cues to intensified use cannot be distinguished through observational research. In order to do so, a controlled study that is able to separate the individual from social cues would be required.

These findings support a growing body of evidence that drug use and drug-related harm increase following SA cheque issue (Rosen, 2011). For example, the results from our study are consistent with prior aggregate-level results compiled from Insite, a supervised injection facility in Vancouver, showing an immediate increase following monthly SA disbursement 
for both the total number of injections performed and rates of non-fatal overdose (Zlotorzynska et al., 2014). Moreover, there is empirical support for our findings among broader populations of SA recipients. Stephens (2003) found that among households for which SA represents an important portion of their income, amounts spent on consumption increased between $7 \%$ and $20 \%$ in the week following SA receipt, and increases were even larger the day of and the day after SA receipt. Lastly, our results are also consistent with findings among SA recipients that have documented decreases in consumption immediately before SA receipt (Shapiro, 2005; Stephens, 2003).

Another finding to emerge from our analyses is that the temporal association between SA receipt and drug use intensification was found to be even stronger for individuals reporting tripling their usual intensity of use compared to their habitual patterns of use. This finding was consistent across individuals using stimulants, opioids or with polydrug use, and given that the effect appears to be largely driven by each individuals' primary use substance, our findings suggest the effect of SA receipt may motivate a relative change in behavior, characterized by important momentary intensification of typical drug use levels, as opposed to an absolute change in individuals' patterns of use. Taken together, our results indicating that there is a stronger association between the timing of SA receipt the greater the intensification of drug use and confirm aggregate-level observations of increased high-risk drug use and drug related harm, such as binge use and accidental overdose, surrounding SA disbursement (Otterstatter et al., 2016)

These findings further support repeated calls for interventions and policies that may prevent the cyclical increases in drug-related harms associated with monthly coordinated SA disbursement (Riddell \& Riddell, 2006; Zlotorzynska, Wood, Montaner, \& Kerr, 2013). Policies such as staggered or smaller and more frequent SA disbursements may have the potential to decrease drug-related harms and should be tested rigorously, particularly if combined with measures to support housing security, such as the provision in British Columbia that allows for rent payments to be made directly from the government to a recipient's landlord. Such alternatives could have important social, economic and public health implications. Further, given findings of the common co-occurrence of substance use disorders and financial mismanagement (Hamilton \& Potenza, 2012), and how these both relate to delayed discounting, a type of impulsivity associated with harmful behavior, it is also important to assess how such policies may impact financial practices among PWUD and whether they can mitigate some of the socio-economic insecurity to which PWUD can be particularly vulnerable.

This analysis has several limitations. First, our measures of drug use, SA receipt as well as for other sources of income, rely on self-report. While one of the most frequently raised issues of self-reported data is the reliability of disclosure and other forms of reporting bias, this concern should be mitigated by the repetition of follow-up assessments and nearly 20 year relationships between the investigative team and the community (Johnson \& Golub, 2007). As such, we have no reason to suspect that participants would systematically over- or under- report their drug use activity. Second, while we controlled for other primary sources of income, we could not control for the possibility that drug use intensification resulted in an increased need for income and subsequent engagement in income generation activities. 
However, given that the timing of SA receipt is not motivated by prior drug use, potential bias from the endogenous relationship between income and drug use should be minimized. Further, while there may exist cyclical variation in income generating strategies that could affect levels of use, we assume that these would result in conservative biases as people generating income on government cheque issue days would likely have less time to intensify drug use. Third, although we attempted to control for relevant confounding in this nonexperimental setting, the association we found may still have been influenced by individual heterogeneity and unmeasured factors influencing individuals' response to either individuallevel or social-level cues of being paid. Nevertheless, given that the timing of SA receipt is plausibly exogenous and the focus on population average effects of our statistical model, we believe that the relatively large effect sizes are representative of an observed positive population average association between drug use intensification and the timing of SA receipt. Fourth, although we were not able to control for drug prices, our measures of increased drug use were derived on relatively short time frames during which the magnitude of price change, if any, should be relatively small. Moreover, the long study period spanning over eight years should attenuate the risk of bias being introduced in our estimates by price changes coinciding with SA disbursement. Lastly, while our analysis was based on cohort studies involving people who use illicit drugs, given that our study population was characterized by long-term use and high prevalence of mental illness, and the wide-ranging nature of the social safety net in BC, including healthcare and SA delivery policies, caution must be exercised in applying these estimates to other settings.

In conclusion, our results suggest a strong temporal association between SA receipt and an increase in drug use intensity, compared to levels of use at other times. As such, our findings contribute to the disentangling of the causal pathways linking different income sources and drug use. These findings also reinforce a growing body of evidence pointing to the inadvertent harm produced by monthly SA disbursement and suggest that alternative approaches that preserve the important poverty-reducing effects of state-provided benefits but are better able to mitigate any inadvertent, drug-related harm should be tested rigorously.

\section{Supplementary Material}

Refer to Web version on PubMed Central for supplementary material.

\section{Acknowledgments}

The authors thank the study participants for their contribution to the research, as well as current and past researchers and staff. The VIDUS cohort study was supported by the US National Institutes of Health (U01DA038886), the ACCESS cohort study was supported by the US National Institutes of Health (R01DA021525), the ARYS cohort study was supported by the US National Institutes of Health (U01DA038886) and the Canadian Institutes of Health Research (MOP-286532). This study was supported by the Canadian Institutes of Health Research (MOP-142732, MOP-136827). Drs. Kora DeBeck, Kanna Hayashi, MJ Milloy and Lindsey Richardson are supported by Canadian Institutes for Health Research New Investigator Awards. Dr. Kora DeBeck is supported by a Michael Smith Foundation for Health Research / St. Paul's Hospital Foundation-Providence Health Care Career Scholar Award and Drs. M-J Milloy, Bohdan Nosyk and Lindsey Richardson are supported by Michael Smith Foundation for Health Research Scholar Awards. This research was undertaken, in part, thanks to the funding from the Canada Research Chairs program through a Tier 1 Canada Research Chair in Inner City Medicine which supports Dr. Evan Wood. Dr. Bohdan Nosyk holds a St. Paul's Hospital CANFAR Chair in HIV/AIDS Research. 


\section{References}

Anis AH, Sun H, Guh DP, Palepu A, Schechter MT, O'Shaughnessy MV. Leaving hospital against medical advice among HIV-positive patients. CMAJ. 2002; 167(6):633-637. [PubMed: 12358196]

Becker G, Grossman M, Murphy K. Rational addiction and the effect of price on consumption. The American economic review. 1991:237-241.

Bourgois P. The moral economies of homeless heroin addicts: Confronting ethnography, HIV risk, and everyday violence in San Francisco shooting encampments. Substance use \&amp; misuse. 1998; 33(11):2323-2351. [PubMed: 9758016]

Bretteville-Jensen A, Sutton M. The income-generating behaviour of injecting drug-users in Oslo. Addiction. 1996; 91(1):63-79. [PubMed: 8822015]

Brunette DD, Kominsky J, Ruiz E. Correlation of emergency health care use, 911 volume, and jail activity with welfare check distribution. Annals of Emergency Medicine. 1991; 20(7):739-742. [PubMed: 1648313]

Canada Mortgage and Housing Corporation. Rental Market Statistics. 2015. Retrieved from www.cmhc-schl.gc.ca/odpub/esub/64487/64487_2015_B01.pdf

Catalano R, McConnell W. Psychiatric Emergencies: The Check Effect Revisited. Journal of Health and Social Behavior. 1999; 40(1):79. [PubMed: 10331323]

Cebulla A, Heaver C, Smith N, Sutton L. Drugs and Alcohol as Barriers to Employment. 2004 Retrieved from Sheffield.

Chan ACH, Palepu A, Guh DP, Sun H, Schechter MT, O’Shaughnessy MV, Anis AH. HIV-positive injection drug users who leave the hospital against medical advice: the mitigating role of methadone and social support. Journal of Acquired Immune Deficiency Syndromes. 2004; 35(1):56-59. [PubMed: 14707793]

Cohen, M.; Goldberg, M.; Nick, I. Removing barriers to work: Flexible employment options for people with disabilities in BC: Full research report. Canadian Centre for Policy Alternatives; 2008.

Dave D. The effects of cocaine and heroin price on drug-related emergency department visits. Journal of Health Economics. 2006; 25(2):311-333. [PubMed: 16188336]

Deaton A. Policy implications of the gradient of health and wealth. Health Affairs. 2002; 21(2):13-30.

DeBeck K, Shannon K, Wood E, Li K, Montaner J, Kerr T. Income generating activities of people who inject drugs. Drug and Alcohol Dependence. 2007; 91(1):50-56. [PubMed: 17561355]

DeBeck K, Wood E, Qi J, Fu E, McArthur D, Montaner J, Kerr T. Interest in low-threshold employment among people who inject illicit drugs: Implications for street disorder. Int J Drug Policy. 2011; 22(5):376-384. [PubMed: 21684142]

Deering KN, Lyons T, Feng CX, Nosyk B, Strathdee SA, Montaner JS, Shannon K. Client demands for unsafe sex: the socioeconomic risk environment for HIV among street and off-street sex workers. Journal of acquired immune deficiency syndromes. 2013; 63(4):522-531. [PubMed: 23614990]

Deschenes E, Anglin M. Narcotics addiction: related criminal careers, social and economic costs. J Drug Issues. 1991; 21(2):383.

Dobkin C, Puller SL. The effects of government transfers on monthly cycles in drug abuse, hospitalization and mortality. Journal of Public Economics. 2007; 91(11):2137-2157.

Draus PJRJ, Greenwald M. I always kept a job: income generation, heroin use and economic uncertainty in 21st century Detroit. J Drug Uses. 2010; 40:841-869.

Drevets WC, Gautier C, Price JC, Kupfer DJ, Kinahan PE, Grace AA, Mathis CA. Amphetamineinduced dopamine release in human ventral striatum correlates with euphoria. Biol Psychiatry. 2001; 49(2):81-96. [PubMed: 11164755]

Epstein DH, Willner-Reid J, Vahabzadeh M, Mezghanni M, Lin J-L, Preston KL. Real-time electronic diary reports of cue exposure and mood in the hours before cocaine and heroin craving and use. Archives of General Psychiatry. 2009; 66(1):88-94. [PubMed: 19124692]

Erikson PBJ, McGillicuddy P, Halligen A. Crack and prostitution: gender, myths and expereinces. J Drug Uses. 2002; 30:767-788. 
Ettner SL. New evidence on the relationship between income and health. Journal of Health Economics. 1996; 15(1):67-85. [PubMed: 10157429]

Fischer B. Illicit opiates and crime: results of an untreated user cohort study in Toronto. Can J Criminol. 1999; 7(5):377.

Gallet CA. Can Price Get The Monkey Off Our Back? A Meta-Analysis Of Illicit Drug Demand. Health Economics. 2014; 23(1):55-68. [PubMed: 23303721]

Grapendaal, M.; Lewu, E.; Nelen, H., editors. A world of opportunities: life-style and economic behavior of heroin addicts in Amsterdam. Albany, NY: State University of New York Press; 1995.

Halpern SD, Mechem CC. Declining rate of substance abuse throughout the month. The American journal of medicine. 2001; 110(5):347-351. [PubMed: 11286948]

Hamilton KR, Potenza MN. Relations among delay discounting, addictions, and money mismanagement: Implications and future directions. The American journal of drug and alcohol abuse. 2012; 38(1):30-42. [PubMed: 22211535]

Immervoll H. Minimum-income benefits in OECD countries: policy design, effectiveness and challenges. IZA Discussion Papers, No. 4627. 2009

Johnson BD, Golub A. The potential for accurately measuring behavioral and economic dimensions of consumption, prices, and markets for illegal drugs. Drug Alcohol Depend. 2007; 90(Suppl. 1):S16-S26. [PubMed: 16978801]

Jones AM, Wildman J. Health, income and relative deprivation: Evidence from the BHPS. Journal of Health Economics. 2008; 27(2):308-324. [PubMed: 18207266]

Kerr T, Small W, Johnston C, Li K, Montaner JS, Wood E. Characteristics of injection drug users who participate in drug dealing: implications for drug policy. J. Psychoactive Drugs. 2008; 40(2):147152. [PubMed: 18720663]

Koob GF, Bloom FE. Cellular and molecular mechanisms of drug dependence. Science. 1988; 242(4879):715-723. [PubMed: 2903550]

Li X, Sun H, Marsh DC, Anis A. Impact of welfare cheque issue days on a service for those intoxicated in public. Harm Reduction Journal. 2007; 4:12. [PubMed: 17462093]

Long C, DeBeck K, Feng C, Montaner J, Wood E, Kerr T. Income level and drug related harm among people who use injection drugs in a Canadian setting. Int J Drug Policy. 2014; 25(3):458-464. [PubMed: 24380808]

Maher, L. Sexed work: Gender, race and resistance in a Brooklyn drug market. New York: Oxford University Press; 1997.

Marmot M. The influence of income on health: views of an epidemiologist. Health Aff (Millwood). 2002; 21(2):31-46.

Marmot, M., editor. The status syndrome: how social standing affects our health and longevity. New York: Henry Holt \& Company; 2004.

Maynard CCG. Association between week of the month and hospitalization for substance abuse. Psychiatr Serv. 2000; 51(1):31. [PubMed: 10647133]

Nelson K. Mechanisms of poverty alleviation: anti-poverty effects of non-means-tested and meanstested benefits in five welfare states. Journal of European Social Policy. 2004; 14(4):371-390.

Nosyk B, Sun H, Guh D, Oviedo-Joekes E, Marsh DC, Brissette S, Anis AH. An empirical comparison of eight health status measures for chronic opioid dependence. Journal of clinical epidemiology. 2010; 63(10):1132-1144. [PubMed: 20236799]

Otterstatter MC, Amlani A, Guan H, Richardson L, Buxton JA. Illicit drug overdose deaths resulting from income assistance payments: Analysis of the 'check effect'using daily mortality data. International Journal of Drug Policy. 2016

Petry N. Effects of income on polysubstance abuse: a comparison of alcohol, cocaine, and heroin abusers. Addiction. 2000; 95:706-717.

Pickett TSR, Abu-Laban R. Association between Mental Health Apprehensions (MHAs) by police and montghly income assistance (welfare) payments. Can J Psychiatry. 2015; 60(3) HIV and addiction treatment interruption. 
Province of British Columbia. BC Employment and Assistance Rate Tables. 2016a. Retrieved from http://www2.gov.bc.ca/gov/content/governments/policies-for-government/bcea-policy-andprocedure-manual/bc-employment-and-assistance-rate-tables

Province of British Columbia. Income Assistance Payment Dates. 2016b. Retrieved from http:// www2.gov.bc.ca/gov/content/family-social-supports/income-assistance/payment-dates

Rhodes T. Risk environments and drug harms: a social science for harm reduction approach. International Journal of Drug Policy. 2009; 20(3):193-201. [PubMed: 19147339]

Rhodes T, Kimber J, Small W, Fitzgerald J, Kerr T, Hickman M, Holloway G. Public injecting and the need for 'safer environment interventions' in the reduction of drug-related harm. Addiction. 2006; 101(10):1384-1393. [PubMed: 16968336]

Richardson L, Wood E, Kerr T. The impact of social, structural and physical environmental factors on transitions into employment among people who inject drugs. Social Science and Medicine. 2013; 76(1):126-133. [PubMed: 23157930]

Riddell C, Riddell R. Welfare Checks, Drug Consumption, and Health Evidence from Vancouver Injection Drug Users. J Human Resoures. 2006; 41(1):138-161.

Rosen MI. The 'check effect' reconsidered. Addiction. 2011; 106(6):1071-1077. [PubMed: 21338431]

Rosen MI, McMahon TJ, Lin H, Rosenheck RA. Effect of Social Security payments on substance abuse in a homeless mentally ill cohort. Health Services Research. 2006; 41(1):173-191. [PubMed: 16430606]

Saffer H, Chaloupka F. The demand for illicit drugs. Economic Inquiry. 1999; 37(3):401-411.

Shaner A, Eckman TA, Roberts LJ, Wilkins JN, Tucker DE, Tsuang JW, Mintz J. Disability income, cocaine use, and repeated hospitalization among schizophrenic cocaine abusers--a governmentsponsored revolving door? N Engl J Med. 1995; 333(12):777-783. [PubMed: 7643886]

Shannon K, Kerr T, Allinott S, Chettiar J, Shoveller J, Tyndall MW. Social and structural violence and power relations in mitigating HIV risk of drug-using women in survival sex work. Soc Sci Med. 2008; 66(4):911-921. [PubMed: 18155336]

Shapiro JM. Is there a daily discount rate? Evidence from the food stamp nutrition cycle. Journal of Public Economics. 2005; 89(2):303-325.

Sherman S, Latkin C. Drug users' involvement in the drug economy: implications for harm reduction and HIV prevention programs. J U Health. 2002; 79(2):266-277.

Small W, Maher L, Lawlor J, Wood E, Shannon K, Kerr T. Injection drug users' involvement in drug dealing in the downtown eastside of Vancouver: social organization and systemic violence. Int $\mathrm{J}$ Drug Policy. 2013; 24(5):479-487. [PubMed: 23664788]

Small W, Rhodes T, Wood E, Kerr T. Public injection settings in Vancouver: physical environment, social context and risk. International Journal of Drug Policy. 2007; 18(1):27-36. [PubMed: 17689341]

Small W, Shoveller J, Moore D, Tyndall M, Wood E, Kerr T. Injection drug users' access to a supervised injection facility in Vancouver, Canada: the influence of operating policies and local drug culture. Qualitative Health Research. 2011; 21(6):743-756. [PubMed: 21378259]

Stephens M. “ 3rd of tha Month”: Do Social Security Recipients Smooth Consumption Between Checks? American Economic Review. 2003:406-422.

Strathdee SA, Patrick DM, Currie SL, Cornelisse PG, Rekart ML, Montaner JS, O'Shaughnessy MV. Needle exchange is not enough: lessons from the Vancouver injecting drug use study. AIDS. 1997; 11(8):F59-F65. [PubMed: 9223727]

Svikis DS, Pickens RW, Schweitzer W, Johnson E, Haug N. Weekly patterns of drug treatment attendance. American Journal of Public Health. 1999; 89(5):752-755. [PubMed: 10224989]

Swartz JA, Hsieh Cm, Baumohl J. Disability payments, drug use and representative payees: an analysis of the relationships. Addiction. 2003; 98(7):965-975. [PubMed: 12814502]

The Economist Data Team. Worldwide cost of living survey- September 2015. Mar 10. 20162016 Retrieved from http://www.economist.com/blogs/graphicdetail/2016/03/daily-chart-4

Ti LRL, DeBeck K, Nguyen P, Montaner J, Wood E, Kerr T. The impact of engagement in street-based income generation activities on stimulant drug use cessation among people who inject drugs. Drug and Alcohol Dependence. 2014; 141:58-64. [PubMed: 24909853] 
Tweddle A, Battle K, Torjman S. Welfare in Canada, 2014. The Caledon Institute of Social Policy. 2015

Tyndall MW, Currie S, Spittal P, Li K, Wood E, O’Shaughnessy MV, Schechter MT. Intensive injection cocaine use as the primary risk factor in the Vancouver HIV-1 epidemic. AIDS. 2003; 17(6):887893. [PubMed: 12660536]

Verheul G, Singer SM, Christenson JM. Mortality and morbidity associated with the distribution of monthly welfare payments. Academic Emergency Medicine. 1997; 4:118-123. [PubMed: 9043538]

Volkow N, Fowler J, Wang G, Baler R, Telang F. Imaging dopamine's role in drug abuse and addiction. Neuropharmacology. 2009; 56(Suppl 1):3-8. [PubMed: 18617195]

Volkow N, Wang G, Fowler J, Gatley S, Ding Y, Logan J, Lieberman J. Relationship between psychostimulant-induced" high" and dopamine transporter occupancy. Proceedings of the National Academy of Sciences. 1996; 93(19):10388-10392.

Walker, R. Social Security And Welfare: Concepts And Comparisons: Concepts and Comparisons. London: McGraw-Hill; 2004.

Wood E, Stoltz JA, Li K, Montaner JS, Kerr T. Changes in Canadian heroin supply coinciding with the Australian heroin shortage. Addiction. 2006; 101(5):689-695. [PubMed: 16669902]

Wood E, Stoltz JA, Montaner JS, Kerr T. Evaluating methamphetamine use and risks of injection initiation among street youth: the ARYS study. Harm Reduct. J. 2006; 3:18. [PubMed: 16723029]

Zlotorzynska M, Milloy M-J, Richardson L, Montaner J, Wood E, Kerr T. Timing of social assistance payment and overdose patterns at a Canadian supervised injection facility. Int J Drug Policy. 2014; 25:736-739. [PubMed: 24795288]

Zlotorzynska M, Wood E, Montaner J, Kerr T. Supervised injection sites: Prejudice should not trump evidence of benefit. Canadian Medical Association Journal. 2013; 185(15):1303-1304. [PubMed: 24043659] 


\section{Research Highlights}

- $\quad$ Social assistance (SA) disbursement has been linked to increased drugrelated harm.

- This analysis investigates the effect of SA receipt on drug use intensification.

- $\quad$ Past week average use was compared to the average use in the previous 6 months.

- $\quad$ SA payments in the past week are associated with drug use intensification.

- Varying the timing and frequency of SA disbursement may mitigate drug-related harm. 


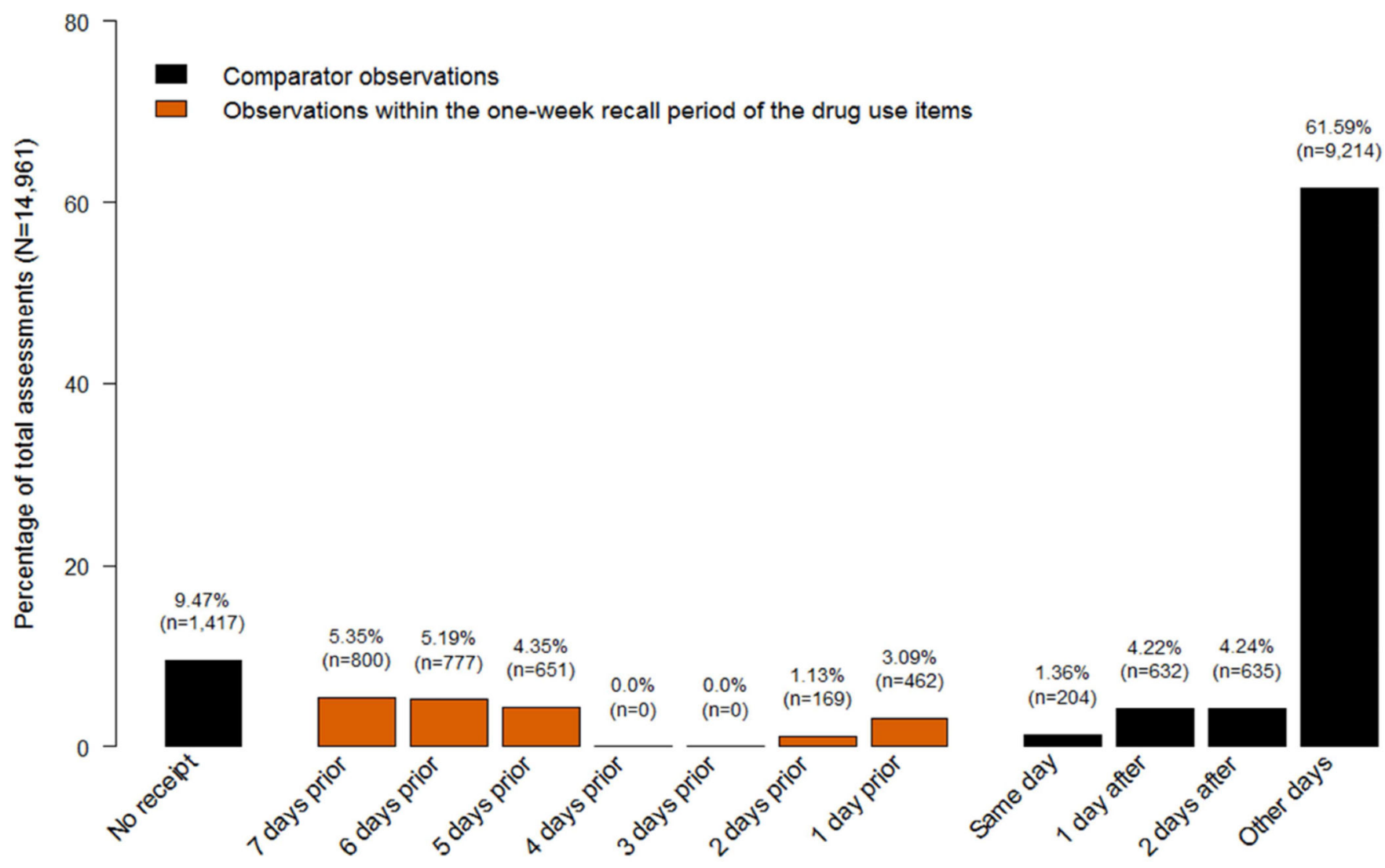

Figure 1. Frequency and timing of social assistance receipt with respect to assessment date Biannual assessments occurred only on weekdays, and given SA disbursement occurring on the last Wednesday of every month, there were no 3- and 4-days prior observations. 


\author{
All use \\ $100 \%$ drug use increase \\ $40 \%$ drug use increase \\ $200 \%$ drug use increase \\ $100 \%$ increase primary drug only \\ Frequency increase from non-daily use to daily use

\section{Primary Opioids Use \\ $100 \%$ drug use increase \\ Primary Stimulants Use \\ $100 \%$ drug use increase}

\section{Polydrug Use \\ $100 \%$ drug use increase} \\ $S A$ receipt timing relative to assessment completion \\ All use, $100 \%$ increase \\ 7 days prior \\ 6 days prior \\ 5 days prior \\ 2 days prior \\ 1 day prior \\ Same day \\ 1 day after \\ 2 days after
}

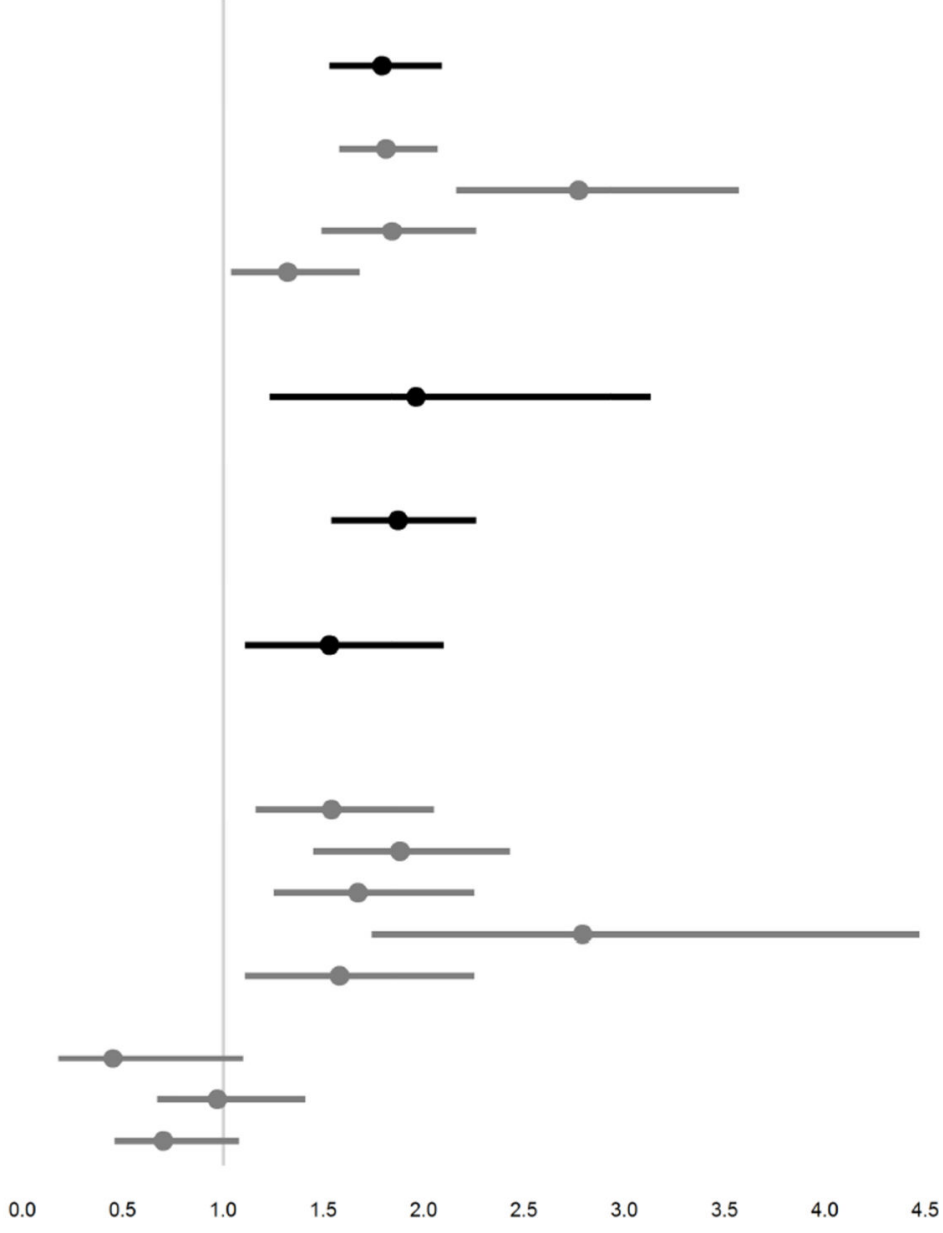

Adjusted Odds Ratios with $95 \%$ Confidence Intervals

Figure 2. Increased drug use associated with Social Assistance receipt within the one-week recall period of the drug use items included in the biannual assessments

The indicator of increased drug use was defined as the percentage increase in the average times per day a given drug was used. The outcome indicators are defined comparing drug use during the last week to drug use during the last six months. Primary drug use was defined as either daily use of a drug or the drug with the highest frequency of use, among either opioids (heroin, methadone, morphine or other prescription opioids) or stimulants (cocaine, crack cocaine, methamphetamine). Polydrug use was defined as reporting a combination of more than one primary drug among any of the aforementioned illicit drugs. Day-by-day results refer to SA receipt timing relative to biannual assessment completion. 


\section{Table 1}

Baseline participant characteristics, stratified by reporting of social assistance receipt within the one-week recall period of the drug use items at least once over the study period.

\begin{tabular}{|c|c|c|c|c|}
\hline & $\begin{array}{l}\text { Total } \\
\text { N }(\%)\end{array}$ & Yes & No & P-value \\
\hline Number of participants & $2661(100)$ & $1415(53.2)$ & $1246(46.8)$ & \\
\hline Age (Median [IQR]) & $36.1[23.6-45.2]$ & $38.9[26.6-46.2]$ & $29.0[22.2-42.9]$ & $<.001$ \\
\hline Male & $1798(67.6)$ & $949(67.1)$ & $849(68.1)$ & 0.556 \\
\hline White & $1651(62.0)$ & $856(60.5)$ & $795(63.8)$ & 0.079 \\
\hline Relationship Status ${ }^{a}$, L6M & 775 (29.6) & $413(29.6)$ & $362(29.5)$ & 0.945 \\
\hline Education, less than high school & $1428(54.6)$ & $751(54.1)$ & $677(55.1)$ & 0.600 \\
\hline Lived in DTES, ever & $1255(69.0)$ & $801(71.7)$ & $454(64.7)$ & 0.002 \\
\hline Homelessness, ever & $2265(85.3)$ & $1202(85.1)$ & $1063(85.6)$ & 0.738 \\
\hline Injection, ever & $1994(74.9)$ & $1177(83.2)$ & $817(65.6)$ & $<.001$ \\
\hline Years since first injection (Median [IQR]) & $16.2[8.0-26.3]$ & $17.9[9.6-27.7]$ & $13.6[6.3-24.4]$ & $<.001$ \\
\hline Overdosed, ever & $1166(44.1)$ & $662(47.0)$ & $504(40.9)$ & 0.002 \\
\hline HIV Positive & $750(28.2)$ & $451(31.9)$ & $299(24.0)$ & $<.001$ \\
\hline HCV Positive & $1670(62.8)$ & $1021(72.2)$ & $649(52.1)$ & $<.001$ \\
\hline Mental illness, ever & $1447(54.4)$ & $749(52.9)$ & $698(56.0)$ & 0.111 \\
\hline Cohort & & & & $<.001$ \\
\hline ACCESS & $747(28.1)$ & $450(31.8)$ & $297(23.8)$ & \\
\hline VIDUS & $1077(40.5)$ & $672(47.5)$ & $405(32.5)$ & \\
\hline ARYS & $837(31.5)$ & $293(20.7)$ & $544(43.7)$ & \\
\hline Year of baseline assessment & & & & $<.001$ \\
\hline $2005-2006$ & $1442(54.2)$ & $882(62.3)$ & $560(44.9)$ & \\
\hline $2007-2009$ & $924(34.7)$ & $422(29.8)$ & $502(40.3)$ & \\
\hline $2010-2013$ & $295(11.1)$ & $111(7.8)$ & $184(14.8)$ & \\
\hline Number of follow ups (Median [IQR]) & $5.0[2.0-10.0]$ & $8.0[5.0-12.0]$ & $2.0[1.0-5.0]$ & $<.001$ \\
\hline
\end{tabular}

Legally married/common law/regular partner vs. Other

L6M: last six months; DTES: Vancouver's Downtown East Side; IQR: interquartile range; ACCESS: AIDS Care Cohort to evaluate Exposure to Survival Services; VIDUS: Vancouver Injection Drug Users Study; ARYS: At-Risk Youth Study 


\section{Table 2}

Income and drug use characteristics, stratified by assessments at which participants reported social assistance receipt occurring within the one-week recall period of the drug use items.

\begin{tabular}{|c|c|c|c|c|}
\hline & $\begin{array}{l}\text { Total } \\
\text { N }(\%)\end{array}$ & Yes & No & P-value $a$ \\
\hline Number of observations & $14961(100)$ & $2859(19.1)$ & $12102(80.9)$ & \\
\hline Primary source of income, L6M & & & & $<.001$ \\
\hline Social Assistance & $9502(63.5)$ & $1962(68.6)$ & $7540(62.3)$ & \\
\hline Employment & $1272(8.5)$ & $155(5.4)$ & $1117(9.2)$ & \\
\hline Sex work & $513(3.4)$ & $91(3.2)$ & $422(3.5)$ & \\
\hline Street-based income generation & $681(4.6)$ & $146(5.1)$ & $535(4.4)$ & \\
\hline Drug dealing and other acquisitive crime & $1587(10.6)$ & $294(10.3)$ & $1293(10.7)$ & \\
\hline Others & $1406(9.4)$ & $211(7.4)$ & $1195(9.9)$ & \\
\hline Primary drug use, L6M & & & & 0.041 \\
\hline Opioids & $2208(14.8)$ & $392(13.7)$ & $1816(15.0)$ & \\
\hline Stimulants & $9801(65.5)$ & $1862(65.1)$ & $7939(65.6)$ & \\
\hline Polydrug & $2952(19.7)$ & $605(21.2)$ & $2347(19.4)$ & \\
\hline \multicolumn{5}{|l|}{ Intensity of use ${ }^{b}$, L6M (Median [IQR]) } \\
\hline All drug users & $4.0[2.0-8.0]$ & $4.0[2.0-10.0]$ & $4.0[2.0-8.0]$ & 0.003 \\
\hline Primary opioids users & $3.0[2.0-4.0]$ & $3.0[2.0-5.0]$ & $3.0[2.0-4.0]$ & 0.127 \\
\hline Primary stimulants users & $4.0[2.0-8.0]$ & $4.0[2.0-10.0]$ & $4.0[2.0-8.0]$ & 0.013 \\
\hline Polydrug users & $5.0[3.0-10.0]$ & $5.0[3.0-10.0]$ & $5.0[3.0-10.0] 0.450$ & \\
\hline Any injection in public, L6M & $3545(23.7)$ & $670(23.4)$ & $2875(23.8)$ & 0.716 \\
\hline Any injection, L6M & $10231(68.4)$ & $1999(69.9)$ & $8232(68.0)$ & 0.050 \\
\hline Accessed social services, L6M & $10345(69.1)$ & $1984(69.4)$ & $8361(69.1)$ & 0.749 \\
\hline Current participation in OAT & $6268(41.9)$ & $1256(43.9)$ & $5012(41.4)$ & 0.014 \\
\hline Reported $40 \%$ drug-specific use increase ${ }^{c}$ & $1153(7.7)$ & $329(11.5)$ & $824(6.8)$ & $<.001$ \\
\hline Reported $100 \%$ drug-specific use increase ${ }^{c}$ & $839(5.6)$ & $241(8.4)$ & $598(4.9)$ & $<.001$ \\
\hline Reported $200 \%$ drug-specific use increase ${ }^{c}$ & $272(1.8)$ & $106(3.7)$ & $166(1.4)$ & $<.001$ \\
\hline Reported change from non-daily use to daily ${ }^{c}$ & $381(2.6)$ & $90(3.1)$ & $291(2.4)$ & 0.023 \\
\hline
\end{tabular}

L6M: last six months; OAT: Opioid agonist treatment.

${ }^{a}$ Chi-squared tests for categorical variables.

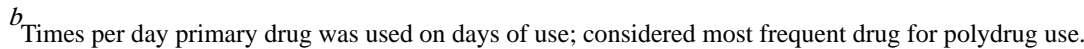

${ }^{c}$ Within one-week recall period compared to L6M. 
Table 3

GEE analysis of factors associated with intensified drug use ${ }^{a}$ following social assistance receipt among people who use illicit drugs in Vancouver, Canada $\left(2005-2013 ; \mathrm{N}=2,661^{b}\right)$.

\begin{tabular}{|c|c|c|c|c|}
\hline & \multicolumn{2}{|l|}{ Bivariate } & \multicolumn{2}{|l|}{$\underline{\text { Multivariable }}$} \\
\hline & $\begin{array}{l}\text { Unadjusted OR } \\
(95 \% \text { CI })\end{array}$ & P-value & $\begin{array}{l}\text { Adjusted OR } \\
(95 \% \text { CI) }\end{array}$ & P-value \\
\hline SA receipt within recall period $c$ & $1.80(1.54-2.10)$ & $<.001$ & $1.79(1.53-2.09)$ & $<.001$ \\
\hline Age, per year & $1.00(1.00-1.01)$ & 0.193 & $1.01(1.00-1.01)$ & 0.187 \\
\hline Male & $0.99(0.84-1.16)$ & 0.885 & $1.04(0.87-1.24)$ & 0.645 \\
\hline White & $1.00(0.86-1.17)$ & 0.972 & $0.98(0.83-1.14)$ & 0.764 \\
\hline Currently living in DTES & $1.34(1.15-1.55)$ & $<.001$ & $1.27(1.07-1.52)$ & 0.008 \\
\hline Currently unstable housing & $1.22(1.04-1.44)$ & 0.018 & $1.03(0.85-1.24)$ & 0.778 \\
\hline \multicolumn{5}{|l|}{ Primary source of income, L6M } \\
\hline Social Assistance & Reference & & Reference & \\
\hline Employment & $1.15(0.89-1.48)$ & 0.287 & $1.46(1.11-1.92)$ & 0.007 \\
\hline Sex work & $1.40(1.00-1.97)$ & 0.052 & $1.30(0.89-1.89)$ & 0.174 \\
\hline Street-based income generation & $1.21(0.86-1.70)$ & 0.274 & $1.21(0.86-1.72)$ & 0.279 \\
\hline Drug dealing and other acquisitive crime & $1.16(0.92-1.48)$ & 0.209 & $1.11(0.86-1.43)$ & 0.415 \\
\hline Other $^{d}$ & $1.19(0.93-1.51)$ & 0.171 & $1.26(0.99-1.62)$ & 0.064 \\
\hline \multicolumn{5}{|l|}{ Primary drug use, L6M and OAT receipt $e$} \\
\hline Opioids, not on OAT & Reference & & Reference & \\
\hline Stimulants, not on OAT & $1.04(0.77-1.41)$ & 0.780 & $1.15(0.85-1.55)$ & 0.379 \\
\hline Polydrug, not on OAT & $1.42(1.02-1.98)$ & 0.037 & $1.31(0.93-1.83)$ & 0.123 \\
\hline Opioids, on OAT & $1.05(0.69-1.59)$ & 0.830 & $1.10(0.72-1.68)$ & 0.649 \\
\hline Stimulants, on OAT & $1.36(1.00-1.83)$ & 0.047 & $1.44(1.06-1.95)$ & 0.020 \\
\hline Polydrug, on OAT & $1.54(1.08-2.20)$ & 0.017 & $1.45(1.02-2.08)$ & 0.041 \\
\hline Any injection in public, L6M & $1.48(1.26-1.74)$ & $<.001$ & $1.49(1.24-1.78)$ & $<.001$ \\
\hline HIV positive & $1.05(0.90-1.24)$ & 0.534 & $1.07(0.90-1.26)$ & 0.449 \\
\hline $\mathrm{HCV}$ positive & $1.20(1.00-1.45)$ & 0.053 & $0.97(0.77-1.23)$ & 0.812 \\
\hline Mental illness, ever & $1.14(0.98-1.33)$ & 0.088 & $1.23(1.06-1.44)$ & 0.008 \\
\hline
\end{tabular}

Increased drug use was a composite measure defined as either: (i) a drug-specific increase in the frequency of use of at least $40 \%$; or (ii) a change from non-daily to daily use of an illicit drug; or (iii) an increase in the number of different drugs used daily.

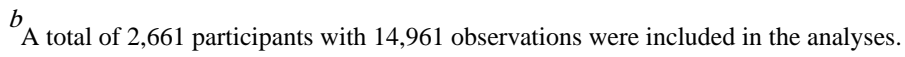

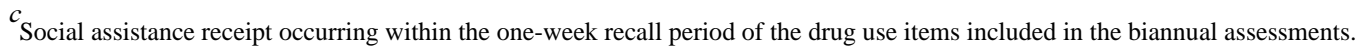

Includes transfers from partners and family members, student loans, selling personal items, widow's pensions, and other reported responses captured in an open text field.

Interaction term used in the model to control for substance-specific differential effect of OAT. GEE: Generalized estimating equations; SA: Social assistance; OR: odds ratio; CI: confidence interval; DTES: Vancouver's Downtown East Side; L6M: last six months; OAT: Opioid agonist treatment. 